\title{
Airways Disease: Phenotyping Heterogeneity Using Measures of Airway Inflammation
}

\author{
Salman Siddiqui, MRCP and Christopher E. Brightling, MRCP, PhD
}

\begin{abstract}
Despite asthma and chronic obstructive pulmonary disease being widely regarded as heterogeneous diseases, a consensus for an accurate system of classification has not been agreed. Recent studies have suggested that the recognition of subphenotypes of airway disease based on the pattern of airway inflammation may be particularly useful in increasing our understanding of the disease. The use of non-invasive markers of airway inflammation has suggested the presence of four distinct phenotypes: eosinophilic, neutrophilic, mixed inflammatory and paucigranulocytic asthma. Recent studies suggest that these subgroups may differ in their etiology, immunopathology and response to treatment. Importantly, novel treatment approaches targeted at specific patterns of airway inflammation are emerging, making an appreciation of subphenotypes particularly relevant. New developments in phenotyping inflammation and other facets of airway disease mean that we are entering an era where careful phenotyping will lead to targeted therapy.
\end{abstract}

Key words: asthma, COPD, eosinophil, inflammation, neutrophil

A sthma and chronic obstructive pulmonary disease (COPD) are the commonest respiratory diseases managed by pulmonologists. The incidence of asthma and COPD continues to rise. ${ }^{1}$ By 2020 , COPD is expected to be the third largest cause of global mortality and currently accounts for $3.5 \%$ of global disability-adjusted life-years. ${ }^{2}$ Exacerbations of airway disease, particularly those that lead to hospital admissions, result in considerable morbidity and mortality as well as an enormous economic burden within health care systems.

Asthma and COPD are characterized by the presence of symptoms of cough, wheeze, and breathlessness with airflow obstruction and underlying airway inflammation. Traditionally, they are distinguished by the presence of variable airflow obstruction, reversibility, and airway hyperresponsiveness (AHR) in asthma and fixed airflow obstruction in COPD. However, neither is specific, and considerable overlap exists, with fixed airflow obstruction a feature in some patients with severe asthma and partial reversibility a frequent feature of COPD. Both diseases are

Salman Siddiqui and Christopher E. Brightling: Institute of Lung Health, Leicester, England.

Correspondence to: Dr. Christopher E. Brightling, Institute for Lung Health, University Hospitals of Leicester, Groby Road, Leicester, LE3 9QP, UK; e-mail: ceb17@le.ac.uk.

DOI 10.2310/7480.2007.00005 composed of a variety of different domains, for example, airflow obstruction (fixed, reversible), AHR, atopy, and airway inflammation. Each patient with airways disease has elements from each domain that contributes to the disease. Within an individual, features from different domains may be associated and change together in response to treatment but may also be dissociated. For example, inflammation is often dissociated from the degree of airway responsiveness in asthma or degree of airflow obstruction in COPD, and a similar disparity may be observed with symptoms. ${ }^{3,4}$ For these reasons, it is important to characterize patients using a composite of measures that describe an individual patient.

In this review article, we concentrate on airway inflammation as a distinct disease domain in asthma and COPD and highlight the clinicopathologic importance of defining phenotypes of disease based on airway inflammation. We also describe new techniques that attempt to combine outcomes from different domains to define patients more accurately and how this may impact on future disease classification and treatment.

\section{New Era of Inflammometry}

The ability to obtain an induced sputum sample using hypertonic saline ${ }^{5}$ has been a major advance in airways disease. Sputum induction is a well-tolerated, safe, and repeatable procedure even in patients with severe disease. ${ }^{6,7}$ A number of other techniques, including the measurement 
of exhaled gases such as nitric oxide (eNO), as well as inflammatory markers in exhaled breath condensates, have been used to characterize airway inflammation in asthma and COPD; however, the clinical utility of these techniques remains to be proven. Measuring airway inflammation has led to the recognition of new asthma phenotypes, identified patients who respond best to corticosteroids, and, most importantly, can reduce exacerbation frequency by targeting anti-inflammatory treatment.

\section{Induced Sputum Eosinophilia Predicts Response to Inhaled and Oral Corticosteroids in Asthma and COPD}

Inhaled corticosteroids (ICSs) have been advocated in all international guidelines for asthma and COPD, with overwhelming evidence for improvement in lung function and symptom scores/quality of life, as well as a reduction in exacerbation frequency. ${ }^{8-13}$ However, despite regular use of ICSs, a large number of patients with asthma continue to have persistent symptoms ${ }^{14}$ and exacerbate symptoms without prior deterioration in day-to-day symptoms. Furthermore, the long-term use of high-dose ICSs in asthma and COPD is associated with clinically important side effects, such as a reduction in bone mineral density and adrenal suppression. ${ }^{15,16}$ Therefore, a strategy aimed at identifying both physiologic and clinical responders to ICSs is clinically important.

In asthma, sputum eosinophilia is associated with a good response to corticosteroids. ${ }^{17,18}$ Little and colleagues demonstrated that a sputum eosinophilia of $>4 \%$ had a positive predictive value of $68 \%$ for predicting a $>15 \%$ forced expiratory volume in 1 second $\left(\mathrm{FEV}_{1}\right)$ response to a 2-week oral corticosteroid trial. ${ }^{19}$ Furthermore, a sputum eosinophilia correlates positively with the degree of improvement to inhaled and oral corticosteroids and seems to be more closely associated with clinical response than eNO or sputum/peripheral blood eosinophilic cationic protein. ${ }^{17}$ Even with so-called refractory asthma, it is questionable whether patients with eosinophilic inflammation have a real corticosteroid resistance. Indeed, a double-blind, placebo-controlled study of intramuscular triamcinolone in severe asthmatics on high-dose inhaled and oral corticosteroids revealed that after 2 weeks of triamcinolone, the sputum eosinophil count was markedly attenuated from a median of 12.6 to $0.2 \%(p<.001)$. Within the triamcinolone group, changes in sputum eosinophilia correlated strongly with improvement in postbronchodilator $\mathrm{FEV}_{1}$ and reduced use of rescue medication. ${ }^{20}$
A number of clinical studies have demonstrated that sputum eosinophilia predicts a response to corticosteroids in COPD. In a single-blind, sequential, placebo-controlled study, treatment with a short-term prednisolone trial had no effect on markers of neutrophilic inflammation (sputum neutrophils, supernatant myeloperoxidase/ elastase); however, a marked reduction in sputum eosinophil count and supernatant eosinophilic cationic protein (ECP) was observed. A subgroup with sputum eosinophils $>3 \%$ had the greatest improvement in $\mathrm{FEV}_{1}$ and quality of life scores. ${ }^{21} \mathrm{~A}$ randomized, placebo-controlled, doubleblind, crossover trial comparing a 2-week course of prednisolone with placebo demonstrated a significant sixfold reduction in the sputum eosinophil count after prednisolone. Stratification of the baseline eosinophil count into tertiles in this study revealed that postbronchodilator $\mathrm{FEV}_{1}$ and symptom scores improved progressively compared with placebo from the lowest to highest eosinophil tertile. ${ }^{22}$ These findings have been confirmed with ICSs in a randomized, double-blind, crossover trial of inhaled mometasone in stable COPD. ${ }^{23}$ Although no treatment benefit was observed overall in terms of symptom scores, a reduction in sputum eosinophilia, or postbronchodilator $\mathrm{FEV}_{1}$, after stratification into tertiles according to the baseline sputum eosinophil count, postbronchodilator $\mathrm{FEV}_{1}$ increased progressively compared with placebo from the least to the most eosinophilic tertile. In contrast, Leigh and colleagues demonstrated that 4 weeks of treatment with inhaled budesonide in patients with moderate to severe airflow obstruction and stable COPD at a more potent beclomethasone dipropionate (BDP)-equivalent dose $(2,000 \mu \mathrm{g} / \mathrm{d})$ normalized sputum eosinophilia compared with placebo and led to significant improvements in dyspnea, postbronchodilator lung function, and quality of life. ${ }^{24}$

Therefore, induced sputum eosinophilia may be used to predict the clinical and physiologic responses to inhaled and oral corticosteroids in asthma and COPD.

\section{Induced Sputum Eosinophilia: Preventing Exacerbations in Asthma and COPD}

Exacerbations represent an enormous health care challenge in asthma and COPD. Corticosteroid reduction studies have consistently shown that induced sputum eosinophilia precedes asthma exacerbations, ${ }^{25-27}$ suggesting that strategies targeting sputum eosinophilia can effectively reduce exacerbations.

Three clinical studies have compared symptom- and guideline-based asthma management to a sputum eosino- 
phil-based strategy. ${ }^{28-30}$ Green and colleagues conducted a randomized, placebo-controlled study in which 74 patients with moderate to severe asthma were assigned to standard clinical management according to national guidelines or a sputum-based strategy group with treatment targeted at normalizing the sputum eosinophil count. ${ }^{28}$ Patients in the sputum management group had significantly fewer asthma exacerbations compared with the guideline management group (35 vs $109 ; p=.01$ ) and significantly fewer patients were admitted to hospital ( 1 vs $6 ; p=.047$ ). Furthermore, the average daily dose of inhaled or oral corticosteroids did not differ between the two groups primarily owing to the identification of a group of patients with noneosinophilic asthma (NEA) in whom corticosteroids were reduced without evidence of deterioration in asthma control. Chlumsky and colleagues conducted a prospective, randomized, controlled study of sputum-based management targeting eosinophils versus standard clinical asthma management in 55 patients with moderate to severe persistent asthma. ${ }^{30}$ Targeting eosinophilia led to a significant reduction in exacerbations (defined as a doubling in symptom frequency/bronchodilator use) compared with the control group (0.22/patient/yr vs $0.78 ; p=.013)$. Furthermore, lung function $\left(\mathrm{FEV}_{1} /\right.$ forced vital capacity) was significantly improved in the sputum group compared with the control group at the end of the 18-month study period. There was no difference between the two groups in ICS use over the study duration. In 117 subjects, Jayaram and colleagues conducted a 2-year, follow-up, multicentre, randomized, parallel-group effectiveness study. ${ }^{29}$ Treatment directed at normalizing the sputum eosinophil count also led to a reduction in exacerbations (79 vs $47 ; p=.04$ ) and increased the time to first exacerbation by 213 days. This benefit was not at the expense of increased therapy in the intervention group. In this study, the inflammatory phenotype of the exacerbations was characterized, and in the sputum guidelines group, eosinophilic, but not noneosinophilic, exacerbations were reduced. Interestingly, the noneosinophilic exacerbations were more common (56\%). The reduction in exacerbations was more apparent in those with moderate to severe disease. This suggests that it is probably most appropriate to apply this technique to the management of difficult-to-treat or refractory asthma but that its use may not be applicable to a primary care population of milder asthmatic patients.

COPD has been traditionally associated with neutrophilic and $\mathrm{CD}^{+} \mathrm{T}$ cell-mediated inflammation at all levels of the airway tree. ${ }^{31,32}$ However, eosinophilic inflammation has been observed in 20 to $40 \%$ of patients with stable
COPD. ${ }^{21-23,33,34}$ Furthermore, during acute exacerbations, the number of eosinophils in bronchial biopsies increases by a factor of 30-fold, with only a 3 -fold increase in neutrophils. ${ }^{33}$ The presence of sputum eosinophilia and not neutrophilia or neutrophil elastase has been associated with the presence of emphysema and high-resolution computed tomography (HRCT) emphysema scores in stable COPD. ${ }^{35,36}$ However, neutrophilic inflammation was associated with small airway changes assessed by HRCT. $^{36}$

Siva and colleagues conducted a randomized trial of traditional British Thoracic Society (BTS) guideline-based management of COPD versus an induced sputum-based strategy, based on eosinophilic airway inflammation. ${ }^{37}$ Eighty-two patients, ages ranging from 45 to 82 years, with a mean (SD) percent predicted $\mathrm{FEV}_{1}$ of 38.2 (15.3), were randomized. The frequency of severe exacerbations (requiring hospital admission) in the sputum management group was significantly less than that in the guideline management group (0.2 exacerbations/patient/yr vs 0.5 ), with a mean reduction of $60 \%$ (95\% confidence interval [CI 5]: $72 \% ; p=.04)$. The average dose of ICS used cumulatively did not differ between study groups, suggesting that the reduction in exacerbation frequency was not simply related to treatment alone. Further prospective studies are awaited to confirm these findings.

Targeting sputum eosinophilia in secondary care is therefore a key strategy in preventing exacerbations in asthma and COPD and is a cost-effective measure for health care providers. ${ }^{28}$

\section{NEA: A Distinct Clinicopathologic Disease Entity}

NEA is defined by clinical symptoms of asthma and AHR in the absence of sputum eosinophilia, ${ }^{38,39}$ defined by a sputum eosinophil count of $<1.01 \%$ (95th percentile value of a healthy population). Noneosinophilic inflammation extends across the entire spectrum of asthma severity, and the phenotype is unlikely to be simply related to corticosteroid treatment. ${ }^{40-43}$ Corticosteroids appear to have limited efficacy in NEA. ${ }^{18} \mathrm{~A}$ recent double-blind, placebo-controlled, crossover trial of inhaled mometasone $400 \mu \mathrm{g}$ once daily in eosinophilic asthma (EA) versus NEA demonstrated that patients with EA had a significant 5.5 doubling-dose improvement in the concentration of methacholine required to cause a $20 \%$ fall in forced expiratory volume in 1 second $\left(\mathrm{PC}_{20} \mathrm{FEV} 1\right)$ after 8 weeks of mometasone compared with placebo versus a 0.5 doubling-dose improvement in patients with NEA. ${ }^{43}$ Furthermore, in the EA group, there was a net 1.0 
improvement in the juniper asthma quality of life score (minimal clinically important difference 0.5) compared with placebo versus a 0.2 improvement in the NEA group $(p<.05)$. A parallel pathologic analysis of endobronchial biopsies revealed that patients with EA had increased submuscosal tissue eosinophilia and thicker lamina reticularis and reticular basement membranes compared with patients with EA. Interestingly, the number of mast cells within the airway smooth muscle did not differ between the two groups but was significantly greater than in matched healthy controls, suggesting that mast cell smooth muscle myositis is fundamental to AHR, a finding that has been borne out by previous pathologic studies in asthma. ${ }^{44}$

Asthmatic smokers have been shown to have reduced eosinophils and increased neutrophils and interleukin-8 (IL-8) in sputum compared with asthmatic nonsmokers, ${ }^{45}$ features similar to those observed in NEA. However, the majority of studies that have assessed patients with NEA have excluded cigarette smokers with a $>10$-pack-year history, and there is no difference in the proportion of exsmokers or never-smokers between NEA and EA in most studies. ${ }^{42}$ Few studies have examined the stability of NEA in stable disease or during an exacerbation. However, the limited data available suggest that NEA is a stable phenotype. Using two sputum samples over a 6-week period, there was moderate agreement between samples (kappa statistic [95\% CI] $0.64[0.4-0.88]) .{ }^{46}$ Perhaps more compelling is that in a long-term reproducibility study that examined seven NEA patients over a mean of 5.3 years, six of seven remained noneosinophilic, indicating substantial long-term reproducibility (kappa 0.77 [0.57-0.97]). ${ }^{46}$ With asthma exacerbations, a subgroup did not develop eosinophilic inflammation. ${ }^{47}$ In occupational asthma, Anees and colleagues assessed the short reproducibility of NEA, collected duplicate sputum samples after 1 week, and reported no change in asthma classification. ${ }^{48}$ Therefore, NEA represents a reproducible asthma phenotype across the entire spectrum of asthma severity, which is corticosteroid nonresponsive. NEA can be further divided based on the neutrophil count into those with neutrophilic asthma or paucigranulocytic asthma in those subjects with a normal eosinophil and neutrophil count (Figure 1).

\section{Neutrophilic Inflammation in Asthma and COPD}

The diagnostic criteria for significant neutrophilic inflammation in induced sputum are $>61 \%$ based on the 95th percentile value in a healthy population ${ }^{46}$ or $>77.7 \%$ based on +2 SD from a healthy population mean. ${ }^{49}$ The differential neutrophil count in induced sputum increases according to age ${ }^{50}$ highlighting the importance of disease groups well matched for age in clinical trials. The diagnostic criterion for sputum neutrophilia based on total counts is $>8.0 \times 10^{6}$ cells/g based on +2 SD from a healthy population mean. ${ }^{49}$ The total neutrophil count is also an important marker of neutrophilic inflammation as the neutrophil is a labile cell and neutrophil numbers are increased by a variety of stimuli. Total neutrophil numbers have been shown to be significantly increased in asthmatic smokers, ${ }^{51}$ in response to bacterial infection with common pathogens in cystic fibrosis ${ }^{52}$ and in response to lipopolysaccharide inhalation in normal subjects. ${ }^{53}$

Neutrophilic inflammation is a potentially important clinical marker in patients with asthma. An isolated sputum neutrophilia was associated with a poor 'response' in terms of $\mathrm{FEV}_{1}$ improvement and doubling-dose improvement in $\mathrm{PC}_{20}$ in a 2-week trial of ICSs in steroid-naive asthmatics. ${ }^{28}$ Furthermore, the clinical profile of patients with isolated neutrophilic inflammation differs, with patients being predominantly older, female, and more likely to be nonatopic but otherwise having clinical and physiologic features similar to those of other asthmatics.

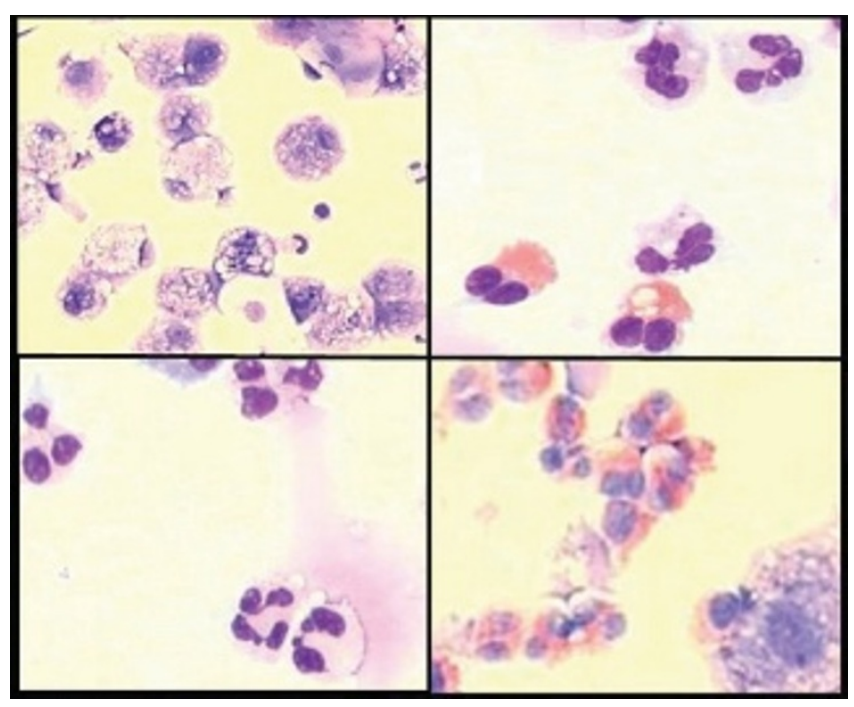

Figure 1. Sputum cytospins from different subjects with asthma illustrate the heterogeneity of the airway inflammation. In the upper left panel, the predominant cells are macrophages with a normal neutrophil and eosinophil count; this cytospin cannot be distinguished from a sample from a healthy control (paucigranulocytic asthma $\times 100$ original magnification); the upper right panel shows combined neutrophilic and eosinophilic inflammation $(\times 400$ original magnification); the lower left panel shows neutrophilic inflammation $(\times 400$ original magnification); and the lower right panel shows eosinophilic inflammation $(\times 400$ original magnification $)$. Adapted from Brightling. ${ }^{98}$ (Romanowsky stain.) 
In neutrophilic asthma, there is evidence of neutrophil activation with increased neutrophil elastase and IL- 8 in induced sputum. ${ }^{54}$ Importantly, there is associated activation of the innate immune response with increased expression of Toll-like receptors 2 and 4 and CD14. ${ }^{55}$ These changes are similar to those observed in bronchiectasis, suggesting that exposure to infection or endotoxin may be important in the pathogenesis of neutrophilic asthma. This is supported by the finding that endotoxin levels were increased in neutrophilic asthma. ${ }^{55}$

Cigarette smoking may be an important modulator of neutrophilic inflammation in asthma. Smoking induces neutrophilic airway inflammation, which correlates directly with the number of pack-years smoked and inversely with postbronchodilator $\mathrm{FEV}_{1} \cdot{ }^{45}$ Smoking cessation in asthma leads to a reduction in neutrophilic inflammation. ${ }^{56}$

In COPD, a variety of studies have demonstrated neutrophilic inflammation in sputum, ${ }^{57-61}$ bronchoalveolar lavage (BAL), ${ }^{62,63}$ and biopsies in COPD. ${ }^{64-66}$ Neutrophilic inflammation in sputum has been associated with both airflow obstruction and $\mathrm{FEV}_{1}$ decline in COPD ${ }^{67}$ Cigarette smoking is associated with neutrophilic inflammation in COPD, but inflammation persists after smoking cessation. Both inhaled and oral corticosteroids have also been shown to have little effect in modulating neutrophilic inflammation in sputum in stable COPD. ${ }^{68,69}$ Bacterial colonization is also associated with neutrophilic airway lumen inflammation in COPD independently from cigarette smoking, suggesting that disordered host defense is an integral driver of neutrophilic inflammation in COPD. $^{70}$

Neutrophilic inflammation is not very susceptible to current anti-inflammatory therapy, and new treatments are required. In recent years, selective phosphodiesterase (PDE) inhibitors (cilomilast, roflumilast) have been developed to selectively block type $4 \mathrm{PDE}$, which is expressed abundantly in inflammatory leukocytes, including neutrophils. ${ }^{71,72}$ PDE4 inhibitors have a variety of antiinflammatory effects on neutrophils, including inhibition of chemotaxis, ${ }^{73}$ suppression of proteolytic enzyme release, inhibition of proinflammatory cytokine release, particularly IL-8 and leukotriene $\mathrm{B}_{4},{ }^{74,75}$ and inhibition of CD11b integrin expression. ${ }^{73}$ In a placebo-controlled trial of 1,411 patients with stable COPD, roflumilast $500 \mu \mathrm{g}$ once daily was shown to reduce exacerbations by $34 \%$ and significantly improve postbronchodilator $\mathrm{FEV}_{1}$ compared with placebo. ${ }^{76}$ Furthermore, the drug was well tolerated, other than class-specific side effects such as nausea, headache, and diarrhea. Cilomilast has been shown to improve symptoms, postbronchodilator lung function, and the percentage of exacerbation-free weeks compared with placebo in stable $\mathrm{COPD}^{77}$ and reduces the submucosal, but not sputum, neutrophil count. ${ }^{78}$

Macrolides may also modulate neutrophilic inflammation, ${ }^{62}$ but there are conflicting data, with one study showing a reduction in sputum total cell count and IL- $8^{63}$ and the other showing no effect. ${ }^{79}$

Neutrophilic inflammation is an important prognostic marker in asthma and COPD; it may exist independently of cigarette smoking and contribute toward $\mathrm{FEV}_{1}$ decline and airflow obstruction. Therefore, neutrophilic inflammation identifies an important inflammatory phenotype, and identification of a sputum neutrophilia will be able to direct future therapies targeted at neutrophilic inflammation.

\section{eNO: Utility in Predicting Eosinophilia, Preventing Exacerbations, and Predicting Response to Treatment}

Assessment of eNO has the appeal of being a simple and repeatable investigation to assess lower airway inflammation, ${ }^{80,81}$ with the additional advantage of being easy to perform and quicker than induced sputum analysis. eNO may have utility in supporting the diagnosis of asthma. An eNO value of $>16 \mathrm{ppb}$ at a flow rate of $200 \mathrm{~mL} / \mathrm{s}$ has a specificity and positive predictive value of $>90 \%$ for predicting asthma (defined as a $\mathrm{PC}_{20}<8 \mathrm{mg} / \mathrm{mL}$ and bronchodilator reversibility of $>12 \%) .{ }^{82}$ However, the utility of eNO in asthma diagnosis in primary care based on asthma symptoms and peak flow variability has not been assessed.

Although eNO seems to correlate closely with eosinophilic airway inflammation in sputum and mucosal tissue, a raised eNO has little utility in predicting a clinically significant sputum eosinophilia $>3 \% .{ }^{83,84}$ There are a number of possible explanations for the discordance between eNO and sputum eosinophilia. It may be possible that neutrophilic inflammation modulates eNO; furthermore, nasal contamination of bronchial eNO (the levels of eNO are 100-fold higher in the upper airways) output may be a confounder despite the traditional notion that bronchial eNO values are obtained with a closed glottis.

The use of eNO to guide response to inhaled and oral corticosteroids is also far from convincing. Smith and colleagues examined the use of eNO versus a conventional symptom-based asthma management strategy to assess the frequency of exacerbations and efficacy of ICS reduction based on the two management regimens in a single-blind, placebo-controlled study of 97 patients. ${ }^{85}$ Management with an eNO-based strategy did not affect the frequency of 
exacerbations compared with the symptom management group. The study did report a significant reduction in the use of ICSs in the eNO group versus conventional management $(370 \mu \mathrm{g} / \mathrm{d}$ vs $641 \mu \mathrm{g} / \mathrm{d} ; p=.003)$. However, these results should be interpreted with caution as the study design did not allow ICS dose reduction in the follow-up phase (phase 2) and the mean dose of ICS in the control group at the end of the treatment optimizing phase (phase 1) of the study was significantly higher than in the eNO group (567 $\mu \mathrm{g} / \mathrm{d}$ vs $292 \mu \mathrm{g} / \mathrm{d} ; p=.003$ ), fixing the control group at a higher daily dose of ICS at the onset of the follow-up phase. Furthermore, eNO was unable to predict significant sputum eosinophilia in approximately one-third of patients. Two further studies, one in adults with mild to moderate asthma ${ }^{86}$ and another in children, ${ }^{87}$ also failed to demonstrate a reduction in asthma exacerbations with corticosteroid therapy targeted at reducing eNO.

Therefore, current evidence does not support the use of eNO to target anti-inflammatory treatment. However, studies investigating the utility of eNO in patients with COPD and in those with severe asthma are eagerly awaited. In addition, the role of measuring other exhaled gases and mediators in exhaled breath condensate in the phenotyping and management of airways disease is unknown.

\section{A More Complex Approach to a Complex Problem: Generation 'Omics'}

One of the limitations of current clinical markers of inflammation in both asthma and COPD is that they fail to capture the complexity and diversity of the inflammatory cascade. As a consequence, significant heterogeneity exists in response to treatments that modulate inflammation.

An emerging approach in recent years to address this problem has been to try to generate phenotype-specific fingerprints of the inflammatory cascade or its genetic regulation. Omics-based technologies-genomics, proteomics, and metabolomics-offer a potential solution to the problem of capturing inflammatory diversity in individuals with airways disease.

\section{Genomics}

With the development of complementary deoxyribonucleic acid (DNA) microarrays, it has become possible to gain information on the level of gene expression for thousands of genes. This opens a new era of biomarker discovery and has the potential to further develop specific expression profiles associated with certain features of airways disease, to predict response to treatment and disease progression. This approach has been applied to cancer, and whether it has applications in airways disease is awaited.

\section{Proteomics}

A vast number of proteins mediate both the normal and aberrant host inflammatory response. Identifying which aspects of the proteome are associated with different patterns of disease expression will allow us to develop effective and selective drugs to target the inflammatory cascade.

Surface-enhanced laser desorption ionization time-offlight mass spectrometry (SELDI-TOF MS) and matrixassisted laser desorption ionization time-of-flight mass spectrometry (MALDI-TOF-MS), together with new developments in more traditional two-dimensional gels, have emerged as powerful tools to examine the proteome and discover potentially novel biomarkers in a variety of airway diseases. ${ }^{88-90}$ SELDI-TOF MS is a combination of miniaturized chromatographic prefractionation on a protein chip followed by MALDI-TOF analysis of subfractions. The process allows capture of proteins in biologic fluids such as BAL or induced sputum supernatants on an immobilized chip that is designed to capture different physicochemical aspects of protein biochemistry (eg, hydrophobicity, metal ion affinity, cationic/anionic properties). ${ }^{91}$ SELDI-TOF offers a variety of advantages; outputs can be generated from very small amounts of biologic fluid at a very high throughput.

A proteomic study of human BAL fluid from smokers with COPD combining SELDI-TOF with mass spectrometry profiling demonstrated that defensins 1 and 2 and calgranulins $\mathrm{A}$ and $\mathrm{B}$ were elevated compared with asymptomatic smokers. ${ }^{88}$ Alpha-defensins are major constituents of neutrophil azurophilic granules, whereas betadefensins are expressed in airway epithelial cells and could contribute to the pathogenesis of COPD by amplifying cigarette smoke-induced and infection-induced inflammatory reactions, leading to lung injury. ${ }^{92}$ Calgranulins may have an important role in neutrophil chemotaxis to the airway and neutrophil elastase-mediated tissue damage seen in COPD.

Large studies using SELDI-TOF-based techniques in well-characterized cohorts of patients with COPD and asthma are eagerly awaited and are likely to play a significant role in drug discovery and biomarker identification in the future. In particular, proteomic approaches 
will enable the development of specific panels of mediators that can be assessed using new multiplex systems, such as Luminex or Meso-Scale, that may be particularly helpful in predicting response to treatment and prognosis.

\section{Metabolomics}

Metabolomics and the related term metabonomics can be defined as the attempt to dynamically measure the metabolic output within a cell, tissue, or organism in response to interventions or changes in their environment. Like proteomics, metabolomics offers promise in the analysis of global inflammation from biologic fluids in asthma and COPD and the possibility of generating a fingerprint metabotype. ${ }^{93,94}$

\section{Multidimensional Phenotyping in Asthma and COPD}

This review has focused on the current and potential future use of measuring airway inflammation in phenotyping airway disease. However, it is important to recognize that this encompasses a single domain of these complex diseases. Both asthma and COPD are characterized by a variety of clinicopathologic domains. Airway physiology (variable vs fixed airflow obstruction), airway inflammation, systemic inflammation (COPD), symptoms and quality of life, genetic predisposition, and environmental/occupational triggers all contribute to the pathogenesis of both diseases. Furthermore, each domain is characterized by a number of measurable variables. The number of variables varies considerably between domains; for example, a large number of candidate genes modulate genetic predisposition, whereas a much more finite number of clinical parameters (eg, $\mathrm{FEV}_{1}, \mathrm{PC}_{20}$, peak flow) define airway physiology. ${ }^{95}$ Most clinical studies predefine asthma and COPD based on a single dimension, for example, variable airflow obstruction in asthma or fixed airflow obstruction in COPD. However, these disease definitions are limiting and do not fully capture the complexity of the disease or acknowledge the multidimensional nature of the disease.

A variety of studies in asthma and COPD have demonstrated that important clinical domains show significant dissociation. Haldar and colleagues examined 271 patients with refractory asthma attending a difficult

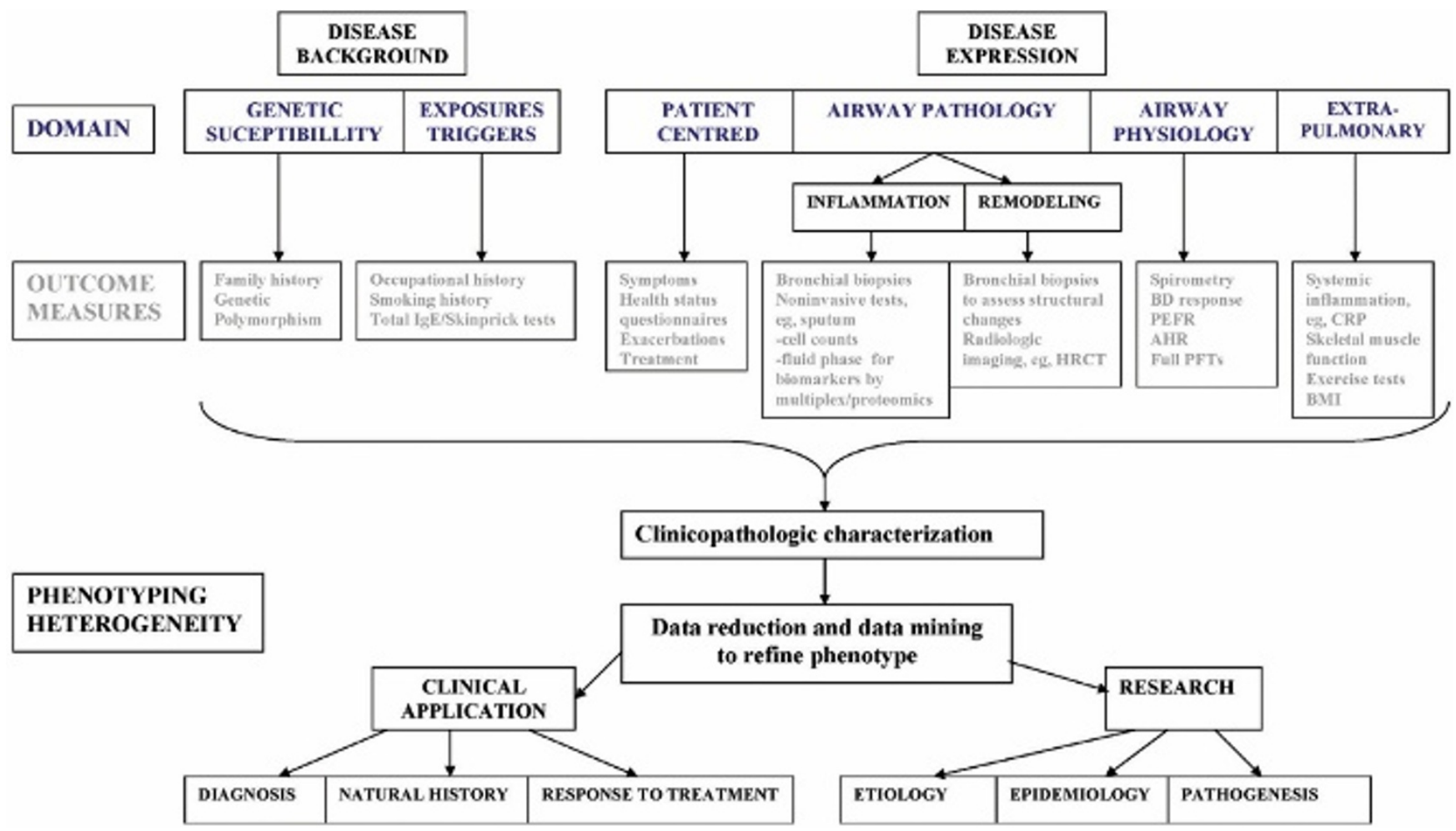

Figure 2. Airway diseases are composed of a number of domains that can be assessed by several outcome measures. The combination of outcome measures allows for phenotyping the heterogeneity, which impacts on clinical management and research. AHR = airway hyperresponsiveness; $\mathrm{BD}$ = bronchodilator; $\mathrm{BMI}=$ body mass index; $\mathrm{CRP}=\mathrm{C}$-reactive protein; HRCT $=$ high-resolution computed tomography, $\mathrm{PEFR}=$ peak flow reading; PFTs $=$ pulmonary function tests. 
asthma clinic in the United Kingdom. ${ }^{96}$ A data reduction technique known as factor analysis minimized 17 variables into five distinct domains: (1) symptom scores, (2) allergy, (3) psychosocial, (4) inflammation, and (5) variable airflow obstruction. This suggests that asthma comprises a number of distinct factors and that the relative contribution of one or more of these factors in a patient determines individual phenotype. Lappere and colleagues studied disease heterogeneity in 114 patients with mild to moderate COPD using factor analysis. ${ }^{3}$ Considerable dissociation was demonstrated between airway function, AHR, and airway inflammation assessed by induced sputum, suggesting that these are discrete, nonoverlapping disease dimensions.

Progress in the study of airways disease may require deviation from the traditional definitions of asthma and COPD. ${ }^{97}$ Furthermore, standardized, nonobjective measurements of different disease-specific variables across domains, within a network of collaborating centres, followed by data mining and data reduction are more likely to allow us to define important disease phenotypes that relate to clinically important outcomes as well as tailoring treatment toward individual patients (Figure 2).

\section{Conclusions}

The measurement of airway inflammation by induced sputum is a useful technique in identifying important clinicopathologic outcomes in asthma and COPD. However, a variety of other parameters capturing the complexity of the inflammatory cascade can now be readily measured, and a collaborative approach between centres with a specialist interest in airways disease combined with advanced data mining is likely to further our understanding of disease phenotypes in the future.

\section{References}

1. Braman SS. The global burden of asthma. Chest 2006;130(1 Suppl):4S-12S.

2. Lopez AD, Mathers $\mathrm{CD}$, Ezzati $\mathrm{M}$, et al. Global and regional burden of disease and risk factors, 2001: systematic analysis of population health data. Lancet 2006;367:1747-57.

3. Lapperre TS, Snoeck-Stroband JB, Gosman MM, et al. Dissociation of lung function and airway inflammation in chronic obstructive pulmonary disease. Am J Respir Crit Care Med 2004;170:499-504.

4. Rosi E, Scano G. Association of sputum parameters with clinical and functional measurements in asthma. Thorax 2000;55:235-8.

5. Pin I, Gibson PG, Kolendowicz R, et al. Use of induced sputum cell counts to investigate airway inflammation in asthma. Thorax 1992; $47: 25-9$.
6. Pizzichini E, Pizzichini MM, Leigh R, et al. Safety of sputum induction. Eur Respir J Suppl 2002;37:9s-18s.

7. Efthimiadis A, Spanevello A, Hamid Q, et al. Methods of sputum processing for cell counts, immunocytochemistry and in situ hybridisation. Eur Respir J Suppl 2002;37:19s-23s.

8. Juniper EF, Kline PA, Vanzieleghem MA, et al. Long-term effects of budesonide on airway responsiveness and clinical asthma severity in inhaled steroid-dependent asthmatics. Eur Respir J 1990;3:11227.

9. Juniper EF, Kline PA, Vanzieleghem MA, et al. Effect of long-term treatment with an inhaled corticosteroid (budesonide) on airway hyperresponsiveness and clinical asthma in nonsteroid-dependent asthmatics. Am Rev Respir Dis 1990;142:832-6.

10. Haahtela T, Jarvinen M, Kava T, et al. Comparison of a beta 2agonist, terbutaline, with an inhaled corticosteroid, budesonide, in newly detected asthma. N Engl J Med 1991;325:388-92.

11. Adams NP, Bestall JB, Malouf R, et al. Inhaled beclomethasone versus placebo for chronic asthma. Cochrane Database Syst Rev 2005;(1):CD002738.

12. Alsaeedi A, Sin DD, McAlister FA. The effects of inhaled corticosteroids in chronic obstructive pulmonary disease: a systematic review of randomized placebo-controlled trials. Am J Med 2002;113:59-65.

13. Man SF, Sin DD. Inhaled corticosteroids in chronic obstructive pulmonary disease: is there a clinical benefit? Drugs 2005;65:579_ 91.

14. Beasley R. The burden of asthma with specific reference to the United States. J Allergy Clin Immunol 2002;109(5 Suppl): S482-9.

15. Mortimer KJ, Tata LJ, Smith CJ, et al. Oral and inhaled corticosteroids and adrenal insufficiency: a case-control study. Thorax 2006;61:405-8.

16. Mortimer KJ, Harrison TW, Tattersfield AE. Effects of inhaled corticosteroids on bone. Ann Allergy Asthma Immunol 2005;94: 15-21.

17. Meijer RJ, Postma DS, Kauffman HF, et al. Accuracy of eosinophils and eosinophil cationic protein to predict steroid improvement in asthma. Clin Exp Allergy 2002;32:1096-103.

18. Pavord ID, Brightling CE, Woltmann G, Wardlaw AJ. Noneosinophilic corticosteroid unresponsive asthma. Lancet 1999;353: 2213-4.

19. Little SA, Chalmers GW, MacLeod KJ, et al. Non-invasive markers of airway inflammation as predictors of oral steroid responsiveness in asthma. Thorax 2000;55:232-4.

20. ten Brinke A, Zwinderman AH, Sterk PJ, et al. "Refractory" eosinophilic airway inflammation in severe asthma: effect of parenteral corticosteroids. Am J Respir Crit Care Med 2004;170: 601-5.

21. Pizzichini E, Pizzichini MM, Gibson P, et al. Sputum eosinophilia predicts benefit from prednisone in smokers with chronic obstructive bronchitis. Am J Respir Crit Care Med 1998;158(5 Pt 1):1511-7.

22. Brightling CE, Monteiro W, Ward R, et al. Sputum eosinophilia and short-term response to prednisolone in chronic obstructive pulmonary disease: a randomised controlled trial. Lancet 2000;356: 1480-5.

23. Brightling CE, McKenna S, Hargadon B, et al. Sputum eosinophilia and the short term response to inhaled mometasone in chronic obstructive pulmonary disease. Thorax 2005;60:193-8. 
24. Leigh R, Pizzichini MM, Morris MM, et al. Stable COPD: predicting benefit from high-dose inhaled corticosteroid treatment. Eur Respir J 2006;27:964-71.

25. Leuppi JD, Salome CM, Jenkins CR, et al. Predictive markers of asthma exacerbation during stepwise dose reduction of inhaled corticosteroids. Am J Respir Crit Care Med 2001;163:406-12.

26. Jatakanon A, Lim S, Barnes PJ. Changes in sputum eosinophils predict loss of asthma control. Am J Respir Crit Care Med 2000; 161:64-72.

27. Pizzichini MM, Pizzichini E, Clelland L, et al. Prednisonedependent asthma: inflammatory indices in induced sputum. Eur Respir J 1999;13:15-21.

28. Green RH, Brightling CE, McKenna S, et al. Asthma exacerbations and sputum eosinophil counts: a randomised controlled trial. Lancet 2002;360:1715-21.

29. Jayaram L, Pizzichini MM, Cook RJ, et al. Determining asthma treatment by monitoring sputum cell counts: effect on exacerbations. Eur Respir J 2006;27:483-94.

30. Chlumsky J, Striz I, Terl M, Vondracek J. Strategy aimed at reduction of sputum eosinophils decreases exacerbation rate in patients with asthma. J Int Med Res 2006;34:129-39.

31. O'Shaughnessy TC, Ansari TW, Barnes NC, Jeffery PK. Inflammation in bronchial biopsies of subjects with chronic bronchitis: inverse relationship of CD8+ T lymphocytes with FEV1. Am J Respir Crit Care Med 1997;155:852-7.

32. Saetta M, Di Stefano A, Turato G, et al. CD8+ T-lymphocytes in peripheral airways of smokers with chronic obstructive pulmonary disease. Am J Respir Crit Care Med 1998;157(3 Pt 1):822-6.

33. Saetta M, Di Stefano A, Maestrelli P, et al. Airway eosinophilia in chronic bronchitis during exacerbations. Am J Respir Crit Care Med 1994;150(6 Pt 1):1646-52.

34. Confalonieri M, Mainardi E, Della PR, et al. Inhaled corticosteroids reduce neutrophilic bronchial inflammation in patients with chronic obstructive pulmonary disease. Thorax 1998;53:583-5.

35. O'Donnell RA, Peebles C, Ward JA, et al. Relationship between peripheral airway dysfunction, airway obstruction, and neutrophilic inflammation in COPD. Thorax 2004;59:837-42.

36. Boschetto P, Quintavalle S, Zeni E, et al. Association between markers of emphysema and more severe chronic obstructive pulmonary disease. Thorax 2006;61:1037-42.

37. Siva R, Green R, Brightling CE, et al. Modulation of eosinophilic airway inflammation in COPD. Eur Respir J 2005;26 Suppl 49:441s.

38. O'Donnell RA, Frew AJ. Is there more than one inflammatory phenotype in asthma? Thorax 2002;57:566-8.

39. Douwes J, Gibson P, Pekkanen J, Pearce N. Non-eosinophilic asthma: importance and possible mechanisms. Thorax 2002;57: 643-8.

40. Gibson PG, Simpson JL, Saltos N. Heterogeneity of airway inflammation in persistent asthma: evidence of neutrophilic inflammation and increased sputum interleukin-8. Chest 2001; 119:1329-36.

41. Wenzel SE, Schwartz LB, Langmack EL, et al. Evidence that severe asthma can be divided pathologically into two inflammatory subtypes with distinct physiologic and clinical characteristics. Am J Respir Crit Care Med 1999;160:1001-8.

42. Godon P, Boulet LP, Malo JL, et al. Assessment and evaluation of symptomatic steroid-naive asthmatics without sputum eosinophi- lia and their response to inhaled corticosteroids. Eur Respir J 2002; 20:1364-9.

43. Berry MA, Morgan A, Green RH, et al. Clinical and pathological features on non-eosinophilic asthma: a distinct asthma phenotype associated with corticosteroid resistance. Thorax 2005;60 Suppl 2:ii4.

44. Brightling CE, Bradding P, Symon FA, et al. Mast-cell infiltration of airway smooth muscle in asthma. N Engl J Med 2002;346:1699705.

45. Chalmers GW, MacLeod KJ, Little SA, et al. Influence of cigarette smoking on inhaled corticosteroid treatment in mild asthma. Thorax 2002;57:226-30.

46. Simpson JL, Scott R, Boyle MJ, Gibson PG. Inflammatory subtypes in asthma: assessment and identification using induced sputum. Respirology 2006;11:54-61.

47. Turner MO, Hussack P, Sears MR, et al. Exacerbations of asthma without sputum eosinophilia. Thorax 1995;50:1057-61.

48. Anees W, Huggins V, Pavord ID, et al. Occupational asthma due to low molecular weight agents: eosinophilic and non-eosinophilic variants. Thorax 2002;57:231-6.

49. Belda J, Leigh R, Parameswaran K, et al. Induced sputum cell counts in healthy adults. Am J Respir Crit Care Med 2000;161(2 Pt 1):475-8.

50. Thomas RA, Green RH, Brightling CE, et al. The influence of age on induced sputum differential cell counts in normal subjects. Chest 2004;126:1811-4.

51. Chalmers GW, MacLeod KJ, Thomson L, et al. Smoking and airway inflammation in patients with mild asthma. Chest 2001;120: 1917-22.

52. Sagel SD, Kapsner R, Osberg I, et al. Airway inflammation in children with cystic fibrosis and healthy children assessed by sputum induction. Am J Respir Crit Care Med 2001;164(8 Pt 1): 1425-31.

53. Nightingale JA, Rogers DF, Hart LA, et al. Effect of inhaled endotoxin on induced sputum in normal, atopic, and atopic asthmatic subjects. Thorax 1998;53:563-71.

54. Simpson JL, Scott RJ, Boyle MJ, Gibson PG. Differential proteolytic enzyme activity in eosinophilic and neutrophilic asthma. Am J Respir Crit Care Med 2005;172:559-65.

55. Simpson JL, Grissell TV, Douwes J, et al. Innate immune activation in neutrophilic asthma and bronchiectasis. Thorax 2007;62(3):2118.

56. Chaudhuri R, Livingston $\mathrm{E}$, McMahon $\mathrm{AD}$, et al. Effects of smoking cessation on lung function and airway inflammation in smokers with asthma. Am J Respir Crit Care Med 2006;174:12733.

57. Peleman RA, Rytila PH, Kips JC, et al. The cellular composition of induced sputum in chronic obstructive pulmonary disease. Eur Respir J 1999;13:839-43.

58. Turato G, Di Stefano A, Maestrelli P, et al. Effect of smoking cessation on airway inflammation in chronic bronchitis. Am J Respir Crit Care Med 1995;152(4 Pt 1):1262-7.

59. Keatings VM, Collins PD, Scott DM, Barnes PJ. Differences in interleukin-8 and tumor necrosis factor-alpha in induced sputum from patients with chronic obstructive pulmonary disease or asthma. Am J Respir Crit Care Med 1996;153:530-4.

60. Beeh KM, Beier J, Kornmann O, et al. Long-term repeatability of induced sputum cells and inflammatory markers in stable, moderately severe COPD. Chest 2003;123:778-83. 
61. Rutgers SR, Postma DS, ten Hacken NH, et al. Ongoing airway inflammation in patients with COPD who do not currently smoke. Chest 2000;117(5 Suppl 1):262S.

62. Tamaoki J. The effects of macrolides on inflammatory cells. Chest 2004;125(2 Suppl):41S-50S.

63. Basyigit I, Yildiz F, Ozkara SK, et al. The effect of clarithromycin on inflammatory markers in chronic obstructive pulmonary disease: preliminary data. Ann Pharmacother 2004;38:1400-5.

64. Hogg JC, Chu F, Utokaparch S, et al. The nature of small-airway obstruction in chronic obstructive pulmonary disease. N Engl J Med 2004;350:2645-53.

65. Pesci A, Majori M, Cuomo A, et al. Neutrophils infiltrating bronchial epithelium in chronic obstructive pulmonary disease. Respir Med 1998;92:863-70.

66. Baraldo S, Turato G, Badin C, et al. Neutrophilic infiltration within the ASM in patients with COPD. Thorax 2004;59:308-12.

67. Stanescu D, Sanna A, Veriter C, et al. Airways obstruction, chronic expectoration, and rapid decline of FEV1 in smokers are associated with increased levels of sputum neutrophils. Thorax 1996;51:26771.

68. Culpitt SV, Maziak W, Loukidis S, et al. Effect of high dose inhaled steroid on cells, cytokines, and proteases in induced sputum in chronic obstructive pulmonary disease. Am J Respir Crit Care Med 1999;160(5 Pt 1):1635-9.

69. Keatings VM, Jatakanon A, Worsdell YM, Barnes PJ. Effects of inhaled and oral glucocorticoids on inflammatory indices in asthma and COPD. Am J Respir Crit Care Med 1997;155:542-8.

70. Sethi S, Maloney J, Grove L, et al. Airway inflammation and bronchial bacterial colonization in chronic obstructive pulmonary disease. Am J Respir Crit Care Med 2006;173:991-8.

71. Hatzelmann A, Schudt C. Anti-inflammatory and immunomodulatory potential of the novel PDE4 inhibitor roflumilast in vitro. J Pharmacol Exp Ther 2001;297:267-79.

72. Bundschuh DS, Eltze M, Barsig J, et al. In vivo efficacy in airway disease models of roflumilast, a novel orally active PDE4 inhibitor. J Pharmacol Exp Ther 2001;297:280-90.

73. Spoelstra FM, Berends C, Dijkhuizen B, et al. Effect of theophylline on CD11b and L-selectin expression and density of eosinophils and neutrophils in vitro. Eur Respir J 1998;12:585-91.

74. Au BT, Teixeira MM, Collins PD, Williams TJ. Effect of PDE4 inhibitors on zymosan-induced IL-8 release from human neutrophils: synergism with prostanoids and salbutamol. $\mathrm{Br} \mathrm{J}$ Pharmacol 1998;123:1260-6.

75. Cortijo J, Villagrasa V, Navarrete C, et al. Effects of SCA40 on human isolated bronchus and human polymorphonuclear leukocytes: comparison with rolipram, SKF94120 and levcromakalim. Br J Pharmacol 1996;119:99-106.

76. Rabe KF, Bateman ED, O'Donnell D, et al. Roflumilast-an oral anti-inflammatory treatment for chronic obstructive pulmonary disease: a randomised controlled trial. Lancet 2005;366:563-71.

77. Rennard SI, Schachter N, Strek M, et al. Cilomilast for COPD: results of a 6-month, placebo-controlled study. Chest 2006;129:5666.

78. Gamble E, Grootendorst DC, Brightling CE, et al. Antiinflammatory effects of the phosphodiesterase-4 inhibitor cilomilast (Ariflo) in chronic obstructive pulmonary disease. Am J Respir Crit Care Med 2003;168:976-82.

79. Banerjee D, Honeybourne D, Khair OA. The effect of oral clarithromycin on bronchial airway inflammation in moderate-to- severe stable COPD: a randomized controlled trial. Treat Respir Med 2004;3:59-65.

80. Kharitonov SA, Yates D, Robbins RA, et al. Increased nitric oxide in exhaled air of asthmatic patients. Lancet 1994;343:133-5.

81. Alving K, Weitzberg E, Lundberg JM. Increased amount of nitric oxide in exhaled air of asthmatics. Eur Respir J 1993;6:1368-70.

82. Dupont LJ, Demedts MG, Verleden GM. Prospective evaluation of the validity of exhaled nitric oxide for the diagnosis of asthma. Chest 2003;123:751-6.

83. Berry MA, Shaw DE, Green RH, et al. The use of exhaled nitric oxide concentration to identify eosinophilic airway inflammation: an observational study in adults with asthma. Clin Exp Allergy 2005;35:1175-9.

84. Payne DN, Adcock IM, Wilson NM, et al. Relationship between exhaled nitric oxide and mucosal eosinophilic inflammation in children with difficult asthma, after treatment with oral prednisolone. Am J Respir Crit Care Med 2001;164(8 Pt 1):1376-81.

85. Smith $\mathrm{AD}$, Cowan JO, Brassett KP, et al. Use of exhaled nitric oxide measurements to guide treatment in chronic asthma. N Engl J Med 2005;352:2163-73.

86. Shaw DE, Berry MA, Thomas M, et al. Asthma exacerbations and exhaled nitric oxide: a randomised controlled trial. Eur Respir J 2006;28 Suppl 50:572s.

87. Pijnenburg MW, Bakker EM, Hop WC, de Jongste JC. Titrating steroids on exhaled nitric oxide in children with asthma: a randomized controlled trial. Am J Respir Crit Care Med 2005;172: $831-6$.

88. Merkel D, Rist W, Seither P, et al. Proteomic study of human bronchoalveolar lavage fluids from smokers with chronic obstructive pulmonary disease by combining surface-enhanced laser desorption/ionization-mass spectrometry profiling with mass spectrometric protein identification. Proteomics 2005;5:2972-80.

89. Sloane AJ, Lindner RA, Prasad SS, et al. Proteomic analysis of sputum from adults and children with cystic fibrosis and from control subjects. Am J Respir Crit Care Med 2005;172:1416-26.

90. Kriegova E, Melle C, Kolek V, et al. Protein profiles of bronchoalveolar lavage fluid from patients with pulmonary sarcoidosis. Am J Respir Crit Care Med 2006;173:1145-54.

91. Wulfkuhle JD, Liotta LA, Petricoin EF. Proteomic applications for the early detection of cancer. Nat Rev Cancer 2003;3:267-75.

92. Wallace AM, He JQ, Burkett KM, et al. Contribution of alpha- and beta-defensins to lung function decline and infection in smokers: an association study. Respir Res 2006;7:76.

93. Nicholson JK, Holmes E, Wilson ID. Gut microorganisms, mammalian metabolism and personalized health care. Nat Rev Microbiol 2005;3:431-8.

94. Nicholson JK, Lindon JC, Holmes E. 'Metabonomics': understanding the metabolic responses of living systems to pathophysiological stimuli via multivariate statistical analysis of biological NMR spectroscopic data. Xenobiotica 1999;29:1181-9.

95. Wardlaw AJ, Silverman M, Siva R, et al. Multi-dimensional phenotyping: towards a new taxonomy for airway disease. Clin Exp Allergy 2005;35:1254-62.

96. Haldar P, Green RH, Berry M, et al. Categorising the asthma phenotype: results of a factor analysis. Thorax 2006;60 Suppl 2:ii53.

97. Hargreave FE, Parameswaran K. Asthma, COPD and bronchitis are just components of airway disease. Eur Respir J 2006;28:264-7.

98. Brightling CE. Clinical applications of induced sputum. Chest 2006;129:1344-8. 